Journal of Case Reports 2018;8(3):169-171

\title{
Reversible Orolingual Dyskinesia: An Unknown Presentation of Hashimoto's Toxic Encephalopathy
}

\author{
Ajantha Keshavaraj, Jasiththa Anpalagan \\ Department of Neurology, Teaching Hospital, Jaffna-40000, Sri Lanka.
}

Corresponding Author:

Dr. Ajantha Keshavaraj

Email: ajanthakeshavaraj@yahoo.com

This is an Open Access article distributed under the terms of the Creative Commons Attribution License (creativecommons.org/ licenses/by/3.0).

Received Accepted Published

December 24, 2017

April 26, 2018

July 10, 2018

\begin{abstract}
Introduction: This report is about a young lady displaying orolingual dyskinesia (OD) caused by Hashithyrotoxicosis (HTx) which was reversed back to normal by short course of both oral carbimazole and parental steroid. Case Report: A 23 year old female presented with throat discomfort followed by emotional lability, excessive talk, associated with protruding movements of tongue and occasionally facial grimacing like movements suggestive of OD. Further, she was tachycardic and had diffuse tender goiter. Her TSH was less than $0.015 \mathrm{mIu} / \mathrm{mL}$ and T4 was $4.62 \mathrm{nmoles} / \mathrm{L}$ while the antiTPO antibodies were elevated to $1903 \mathrm{IU} / \mathrm{mL}$. Her CSF protein was disproportionately elevated $(150 \mathrm{mg} / \mathrm{dL})$ with no cells. These features suggested Hashitoxic encephalopathy. This patient was started with oral carbimazole $15 \mathrm{mg}$ thrice a day for the management of thyrotoxicosis. Two weeks later she was started with intravenous methyl-prednisone to achieve complete recovery of Hashimoto's encephalopathy. At eighth week she achieved 90\% clinical improvement and her anti-TPO level reduced to $1020 \mathrm{IU} / \mathrm{mL}$. Conclusion: OD along with elevated anti-TPO antibodies and thyrotoxicosis could be an indicator of Hashimoto's toxic encephalopathy; that is not yet well studied.
\end{abstract}

Keywords: Carbimazole, Goiter, Hashimoto Disease, Thyrotoxicosis, Sri Lanka.

\section{Introduction}

Orolingual dyskinesia (OD) is characterised by unusual focal semi-rhythmic jerks accompanied with dystonic movements of mouth and tongue [1]. It is usually due to structural lesion in the corresponding basal ganglion and an uncommon manifestation of systemic diseases. Hashithyroiditis (HT) is not an uncommon systemic disorder; generally diagnosed by the presence of anti thyroperoxidase antibodies (anti TPO) in the serum [2]. However, thyrotoxicosis in HT (Hashimoto's thyrotoxicosis) occurs less commonly being under/ misdiagnosed comparing to eu/ hypothyroidism which can manifest transiently at early part of the illness [3].

\section{Case Report}

A 23 year-old female presented with drooling of saliva and throat discomfort for three days. Later, she developed abnormal behaviour in the form of excessive talk, emotional lability which eventually turned into abnormal grimacing like movement in peri-oral region; it was slow, irregular, occasionally protruding and twisting movements of the tongue along with intermittent spontaneous mouth opening/pouting suggestive of OD. She was also anxious, tachycardic and having diffuse warm tender goiter. Her higher function examinations, cranial nerves and peripheral nerves were normal. Full blood count, blood picture, liver function test, slit lamp examination of the eyes, renal function 
test, erythrocyte sedimentation rate, anti-nuclear antibodies, anti-streptolysin-O, anti-TSH receptor (TBII) antibodies, electroencepahlogram, MRI brain and 2D echocardigraphy were also normal. Her cerebro-spinal fluid (CSF) protein was disproportionately elevated $(150 \mathrm{mg} / \mathrm{dL})$ with no cells in CSF and normal glucose. Thyroid gland assessment revealed serum TSH less than 0.015 $\mathrm{mIu} / \mathrm{mL}$ and $\mathrm{T} 4$ of $4.62 \mathrm{nmoles} / \mathrm{L}$.

She was diagnosed with thyrotoxicosis and started with oral carbimazole $15 \mathrm{mg}$ thrice daily and propranolol $40 \mathrm{mg}$ twice daily. After two weeks of initial medications and additional five days parental methyl-prednisone $(0.2 \mathrm{~g} / \mathrm{kg} /$ day) she achieved approximately 50\% and 90\% clinical improvements at second and eighth week respectively. In contrast, her anti-TPO level had insignificantly reduced from $1903 \mathrm{IU} / \mathrm{mL}$ to 1020 $\mathrm{IU} / \mathrm{mL}$ by eighth week (reference value $<9 \mathrm{IU} / \mathrm{mL}$ ).

\section{Discussion}

HT, an autoimmune disease, is the common cause of primary hypothyroidism that occurs 5-10 times more in women than men [4]. The concept on autoimmune disorders related to thyroid disorders has been highly revolutionized in recent past. HT and Grave's Disease (GD) are considered as the parts of two ends of the same spectrum of autoimmune pathogenesis process [5]. On the other hand, genomic scanning studies in humans suggest that these belong to two different and unique disease processes related to thyroid gland [6] which is further supported by the case reports in which the occurrence of HT and GD in the same family and GD followed by HT in the same patient are studied [7-9]. In addition, there is no sensitive biochemical parameters to differentiate each other; the diagnosis principally is made according to both clinical and laboratory investigations. Thus, it cannot be argued that Graves disease and not HTx was the cause of the initial thyrotoxicosis in this patient, because HTx is distinguished by the presence of transient hyperthyroid phase, very high titre anti-TPO antibodies and the absence of antiTSH receptor (TBII) antibodies [10].

TPO antibodies destruct thyrocytes and dysfunction the gland by activating complement cascades; this leads to initial transient thyrotoxicosis followed by surplus damage of thyroid follicles eventually causing overt hypothyroidism. Thus, determination of anti-TPO antibodies would serve as relatively more sensitive tool for the diagnosis of HTx and assessment of its complications. Interestingly, the highest levels of anti-TPO and high prevalence $(80-99 \%)$ of sero-positive cases have been reported with HT while elevated levels of anti-TPO concordantly increase the risk of developing overt hypothyroidism [11].

However, the role of anti-TPO antibodies on central nervous system is debatable; it might give rise to heterogeneous clinical manifestations ranging from cognitive impairment neuropsychiatric symptoms, seizures, stroke-like episodes, hyper-somnolence to transient tremors [2]. Extra-pyramidal manifestations in the form of OD have not yet been reported. A few recent case series done on Hashimoto's encephalopathy showed that simultaneously elevated anti-TPO and CSF protein with no CSF pleocytosis were comparable to our patient with OD [2]. Recently, Blanchin et al. reported that binding of anti-TPO antibodies with cerebellar astrocytes results in Hashimoto's encephalopathy [12]. This evident pledge the importance of further studies on central nervous system presentations related to anti-TPO antibodies.

\section{Conclusion}

OD associated with thyrotoxicosis and highly elevated anti-TPO antibodies might serve as a useful clinical indicator of Hashimoto's thyrotoxic encephalopathy. 
Acknowledgement: Our sincere thanks to Ms. Sorubiga Kunathilagam, Research Assistant, Northern Central Hospital, Jaffna, Srilanka for proof reading the manuscript. Contributors: AK: manuscript editing, patient management; JA: manuscript writing, patient management; AK will act as guarantor. Both authors approved the final version of this manuscript.

Funding: None; Competing interests: None stated.

\section{References}

1. Chen WY, Chen AC, Tsai SJ, Lin JJ. Reversible orolingual dyskinesia related to lithium intoxication (Case study) Acta Neurol. 2013;22:32-35

2. Tang.Y, Xing Y, Lin.MT, Zhang J, Jia J. Hashimoto's encephalopathy cases: Chinese experience. BMC Neurology. 2012;12:60

3. Unnikrishnan AG. Hashitoxicosis: A clinical perspective. Thyroid Research and Practice. 2013;10:5-6.

4. Surks MI, Ortiz E, Daniels GH, Sawin CT, Col NF, Cobin RH, et al. Subclinical thyroid disease: scientific review and guidelines for diagnosis and management. JAMA. 2004;291:228-238.

5. Aust G, Krohn K, Morgernthaler G, et al. "Graves" disease and Hashimoto's thyroiditis in monozygotic twins: case study as well as transcriptomic and immunohistological analysis of thyroid tissues. European
Journal of Endocrinology. 2006;154:13-20.

6. McLachlan SM, Nagayama Y, Pichurin PN, Mizutori Y, Chen CR, Misharin A. The link between Grave's disease and Hashimoto's thyroiditis: a role for regulatory T cells. Endocrinology. 2007;148:5724-5733.

7. Desai MP, Karandikar S. Autoimmune thyroid disease in childhood: a study of children and their families. Indian Pediatr. 1999;36:659-668.

8. Umar H, Muallima N, Adam JM, Sanusi H. Hashimoto's thyroiditis following Graves' disease. Acta Med Indones. 2010;41:31-35.

9. Schaffer A, Puthenpura.V, Marshall I. Recurrent thyrotoxicosis due to both Graves' disease and Hashimoto's thyroiditis in the same three patients. Case reports in Endocrinology. 2016(7):1-4.

10. Iddah MA, Macharia BN. Autoimmune thyroid disorders. ISRN Endocrinology. 2013;509764.

11. Pardo CA, Schiess N. Hashimoto's encephalopathy. Annals of the New York Academy of Sciences. 2008;1142:254-265.

12. Blanchin S, Coffin C, Viader F, Ruf J, Carayon P, Potier $\mathrm{F}$, Portier E, et al. Anti-thyroperoxidase antibodies from patients with Hashimoto's encephalopathy bind to cerebellar astrocytes. Journal of Neuroimmunology. 2007;192:13-20. 